\title{
The Diagnosis and Management of Piriformis Syndrome: Myths and Facts
}

\author{
T.A. Miller, K.P. White, D.C. Ross
}

\begin{abstract}
Piriformis Syndrome (PS) is an uncommon, controversial neuromuscular disorder that is presumed to be a compression neuropathy of the sciatic nerve at the level of the piriformis muscle (PM). The diagnosis is hampered by a lack of agreed upon clinical criteria and a lack of definitive investigations such as imaging or electrodiagnostic testing. Treatment has focused on stretching, physical therapies, local injections, including botulinum toxin, and surgical management. This article explores the various sources of controversy surrounding piriformis syndrome including diagnosis, investigation and management. We conclude with a proposal for diagnostic criteria which include signs and symptoms, imaging, and response to therapeutic injections.
\end{abstract}

\begin{abstract}
RÉSUMÉ: Le diagnostic et le traitement du syndrome piriforme : mythes et réalités. Le syndrome piriforme est une maladie neuromusculaire rare et controversée dont l'étiologie présumée est une neuropathie de compression du nerf sciatique au niveau du muscle pyramidal du bassin. Le diagnostic est entravé par le manque de consensus concernant les critères cliniques diagnostiques et le manque d'études définitives probantes ayant recours à l'imagerie ou à l'électrodiagnostic par exemple. Le traitement met l'accent sur les étirements, la physiothérapie, les injections locales dont des injections de toxine botulique et la chirurgie. Cet article explore les différentes sources de controverse entourant le syndrome du muscle pyramidal du bassin quant à son diagnostic, son évaluation et son traitement. Nous concluons en proposant des critères diagnostiques incluant les signes et les symptômes, l'imagerie et la réponse au traitement par injections.
\end{abstract}

Can J Neurol Sci. 2012; 39: 577-583

This article explores and reviews the controversies surrounding piriformis syndrome (PS) with respect to diagnosis, investigation and treatment. While some authors have argued that PS is analogous to other well accepted compression neuropathies such as carpal tunnel syndrome, there is a wide spectrum of opinions concerning the diagnosis. These range from the belief that cases of true piriformis-induced entrapment exist but are rare, ${ }^{1-5}$ to strongly held skepticism regarding the piriformis muscle's causative role. 6,7 Silver and Leadbetter ${ }^{7}$ reported on a survey of 75 U.S. physiatrists and found only $72 \%$ were confident that PS exists. Moreover, 55\% felt that the disorder was over-diagnosed, while $38 \%$ felt it was underdiagnosed. Still other authors have argued that the syndrome is a symptom complex and represents a myofascial pain disorder rather than an entrapment neuropathy. ${ }^{2,8-10}$

Though many contrasting definitions exist, PS may be defined as a neuromuscular disorder that is presumed to occur when the sciatic nerve is compressed or involved at the level of the piriformis muscle. It has been further subdivided into primary and secondary forms, ${ }^{11,12}$ with primary PS comprising of cases in which sciatic nerve entrapment occurs because of some intrinsic abnormality within the muscle itself (for example anomalous anatomy), ${ }^{13}$ while secondary PS is caused by direct, often blunt trauma to the piriformis muscle.

Stewart ${ }^{14}$ has attempted to bring more consistency to the subject by suggesting diagnostic criteria modeled upon
Wilbourn's ${ }^{15}$ classification of thoracic outlet syndrome. Utilizing these criteria, he describes four distinct clinical subtypes of PS (1) proximal sciatic neuropathies (2) neurogenic PS (3) posttraumatic PS and (4) non specific PS. The five components of diagnostic criteria are 1) signs and symptoms 2) electrodiagnostic findings 3) imaging 4) findings at surgery and 5) response to surgical decompression. To date, no clinical studies have confirmed the usefulness of this classification and in particular, whether patients diagnosed by these criteria respond in a predictable way to treatment.

Other studies report varying incidence of PS (8\% to "rare") in patients presenting with low back/buttock pain. ${ }^{2-5,16-23}$ Many of these studies are hampered by a retrospective design and are weakened by a lack of uniform inclusion criteria. Due to insufficient data, it is difficult to re-classify patients in these studies using Stewart's ${ }^{14}$ criteria. It is not feasible to utilize

From the Departments of Physical Medicine and Rehabilitation and Surgery, Schulich School of Medicine and Dentistry, University of Western Ontario, London, Ontario Canada.

Received April 11, 2011. Final Revisions Submitted April 4, 2012. Correspondence to: Thomas A. Miller, Schulich School of Medicine and Dentistry University of Western Ontario, St. Joseph's Health Care, Room 066, 21 Grosvenor Street, London, Ontario, N6A 1Y6, Canada. Email: tmiller@uwo.ca. 


\section{Table 1: Arguments against Piriformis Syndrome}

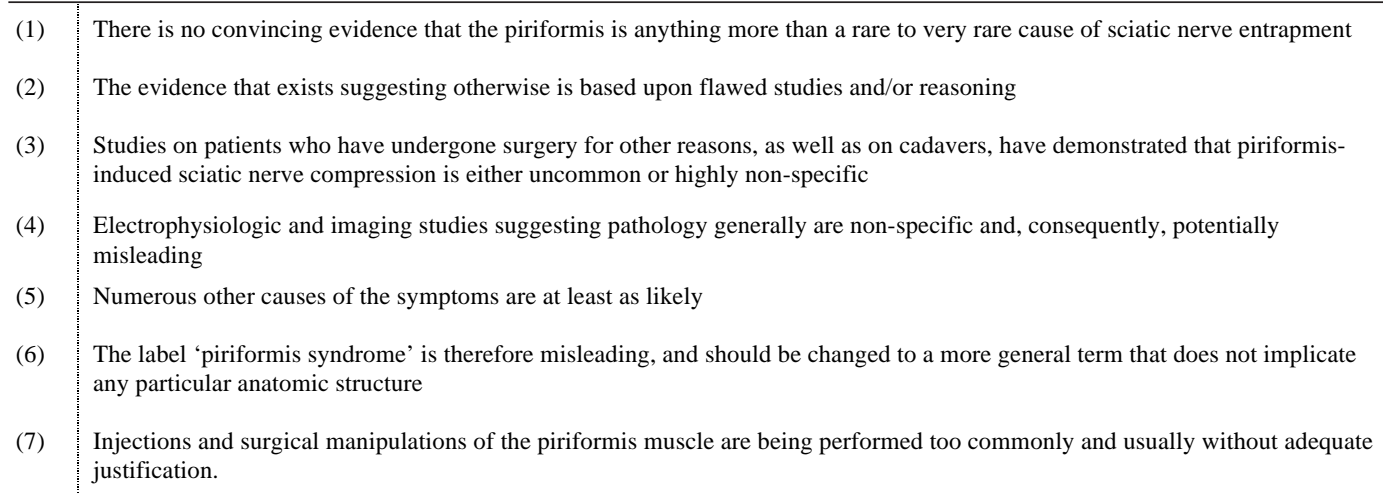

statistical techniques such as meta-analysis to bring clarity to treatment outcomes.

The diagnosis of PS remains difficult and controversial. Review of this subject is hampered by a lack of standardized and accepted diagnostic criteria, making objective, rigorous comparison of different syndromes impossible. It is hoped, that upon review of this article, the reader will have an appreciation of these controversies and an enhanced ability to assess and treat patients presenting with symptoms suggestive of piriformis syndrome.

\section{Clinical Anatomy}

Understanding the manifestations of piriformis-induced entrapment requires familiarity with the anatomy of the muscle and surrounding structures. The piriformis muscle originates at levels S2-S4 on the ventrolateral aspect of the sacrum, and inserts into the piriform fossa of the greater trochanter. ${ }^{24}$ It is innervated by a nerve that originates in the $\mathrm{S} 1$ and $\mathrm{S} 2$ segments. However, considerable variation exists, with the S2 and S3 nerve roots said to pass through the muscle in some symptomatic patients, ${ }^{13}$ and in a large percentage of asymptomatic live controls $^{25}$ and cadavers. ${ }^{26,27}$ The muscle's main functions are 1) to externally rotate the thigh and 2) to abduct the thigh when the hip is flexed. ${ }^{11,22,24}$ It also can be a weak hip flexor.

\section{Clinical Findings}

Due to its location within the sciatic notch and relative to the sacral nerve roots, symptoms that are said to be characteristic of PS are buttock pain which radiates into the ipsilateral thigh and leg. ${ }^{28,29}$ Pain may be exacerbated by prolonged sitting, walking, walking up inclines, and certain other movements. ${ }^{28}$ In a recent review, Hopayian et $\mathrm{al}^{29}$ found reported incidences of buttock pain, low back pain and exacerbation of symptoms due to sitting, to occur in $95 \%, 63 \%$ and $97 \%$ of the population respectively. Estimates of dyspareunia frequency were unreliable in their review.

To diagnose PS, studies of the usefulness and frequency of positive signs/symptoms on physical examination are hampered by the absence of a gold standard. Physical signs however, may be grouped into those which are generally positive for sciatic

Table 2: Arguments for Piriformis Syndrome

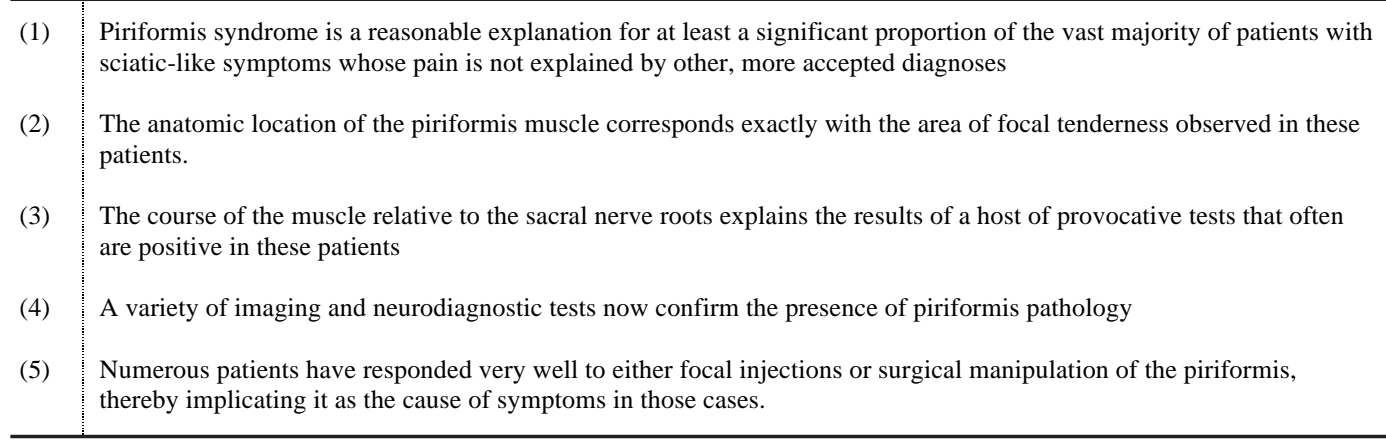




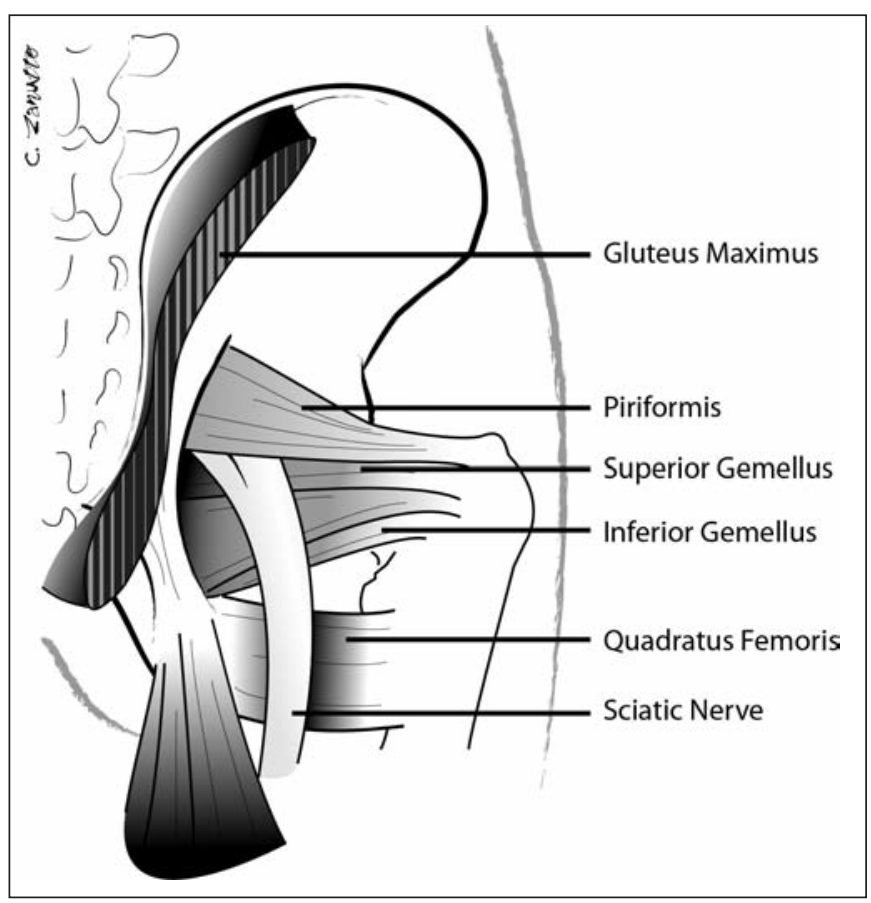

Figure: The Anatomy of the Sciatic nerve, piriformis muscle, and surrounding structures.

nerve "irritation", and those which are thought to be more specific to PS. Of the former, the more common physical signs include limited straight leg raising, a positive Lasègue sign, diminished ankle and/or hamstring reflexes and motor weakness in the L4-S1 myotomes.

While positive findings on physical examination of an individual patient are indicative, the true sensitivity and specificity of any one or combination of these signs remains undetermined. ${ }^{9,14,28,30-32}$

Physical findings thought to be more specific for PS include external tenderness over the sciatic notch, or tenderness of the piriformis muscle on either rectal or vaginal examinations. Three eponymous tests are also suggestive of PS when positive: 1) the Freiberg test (forceful internal rotation of the hip with the patient supine), 2) the Pace test (reproduction of buttock pain with resisted hip abduction), and 3) the Beatty test (reproduction of buttock pain with abduction of the thigh against gravity with patient in lateral decubitus position). Exacerbation of pain in the "FAIR" position (affected hip flexed, adducted and internally rotated) is also a suggestive sign.

\section{Diagnostic Imaging}

Diagnostic imaging is invaluable in ruling out other causes of sciatic nerve irritation such as lumbar disk disease and radiculopathy, however, controversy exists as to the value of imaging modalities to document/confirm the presence of piriformis-related nerve root entrapment.

Although computed tomography may be useful for excluding pathologies such as hematoma and pelvic tumours, it is not generally useful in diagnosing PS. ${ }^{9}$ Magnetic resonance imaging
(MRI) and MR neurography (MRN) have been utilized in a number of studies to diagnose PS, ${ }^{33-36}$ yet these studies are limited to case reports in which specific atypical anatomy was confirmed at time of surgery. In contrast to this, Sayson ${ }^{37}$ and Barton $^{28}$ found pre-operative MRI failed to diagnose atypical anatomy that was found intra-operatively. Further undermining the significance of positive findings on MRI reports, is the study by Russell et $\mathrm{a}^{25}$ who examined the piriformis muscle and sciatic nerves in 100 patients who did not have symptoms of PS. Findings showed that almost one in five subjects had greater than $3 \mathrm{~mm}$ of asymmetry in the size of their piriformis muscles, with a maximum of $8 \mathrm{~mm}$, and the percent of nerve roots that traversed the muscle was $<1 \%$ at S1, but $95 \%$ and $97 \%$ at S2 and S3, respectively. The S4 root was located below the muscle in $95 \%$ of cases.

Magnetic resonance neurography is a relatively new technique that was developed specifically to enhance the imaging of nerves. ${ }^{38-40}$ Filler et $\mathrm{al}^{38}$ defined MRN as "tissueselective imaging directed at identifying and evaluating characteristics of nerve morphology: internal fascicular pattern, longitudinal variations in signal intensity and calibre, and connections and relations to other nerves or plexuses." Its ability to identify peripheral nerve pathology has been documented from numerous body sites, including the neck, back, pelvis and extremities. ${ }^{38}$

In a widely known study, Filler et $\mathrm{al}^{40}$ utilized MRN to prospectively investigate 239 patients with sciatica-like pain, in whom either standard testing had failed to yield a diagnosis or who had a failed lumbar disk surgery. Results showed that $67 \%$ of this group were diagnosed with PS. Using a validated outcomes scale (for lumbar disc surgery), $76 \%$ experienced a good or excellent outcome after piriformis surgery. Due to the specific findings, this study has been cited as validating PS as a true clinical entity. Tiel ${ }^{5}$ however, disagrees with Filler's ${ }^{40}$ conclusions citing methodological and technical problems.

As Tiel $^{5}$ and Stewart ${ }^{14}$ have both pointed out, there is, however, the inherent dilemma of tautology, using treatment response as the standard for diagnosis given the absence of any way to reliably confirm the diagnosis of PS. In essence, it creates a self-fulfilling and highly-convenient prophesy where patients who recover had the condition we thought they had. Moreover, as Filler ${ }^{41}$ argues, the dramatic and prolonged response seen in the majority of patients who had failed all prior attempts at treatment and were treated by guided injection, strongly implicate the piriformis as being somehow involved in the pain mechanism. A critical analysis of the 239 patients with radiating leg pain revealed that roughly half of the cohort $(46 \%)$ had been diagnosed with failed back surgery syndrome, i.e. what is often referred to as the poorly understood condition of post discectomy sciatica. ${ }^{40}$ Similarly, it is difficult to reconcile that $15 \%$ (24 patients) of the 162 patients who had the ultimate diagnosis of PS, had complete relief after a single diagnostic injection. This is difficult to appreciate given the underlying potential pathophysiology.

\section{Electrodiagnostic Testing}

Electrodiagnostic testing is frequently normal in patients with a clinical diagnosis of PS. It is very useful in ruling out other causes with similar symptoms such as radiculopathy, focal 
entrapment neuropathy, and/or a sciatic nerve palsy. Perhaps the first report using electromyelogram (EMG) to diagnose PS was from Kipervas ${ }^{42}$ in 1976. In the English language literature, Synek $^{43}$ in 1987 was the first to write about using electrophysiologic studies for this purpose, reporting the detection of short latency somatosensory evoked potentials in four patients. One of the patients had PS while the other three had spondylopathic cervical radiculopathy, meralgia paraesthetica, and allodynia secondary to a femoral nerve injury. The patient with PS occurred after a fall on a concrete surface, and she demonstrated a sciatic nerve injury with clinical findings of weakness and sensory loss that correlated with the electrophysiology, and axonal loss and denervation on needle EMG, as well as abnormal motor, sensory and $\mathrm{H}$ reflex studies. ${ }^{43}$ This, in our opinion, is a traumatic sciatic nerve injury at the level of the piriformis muscle, and not Piriformis syndrome per se. Benson and Schutzer ${ }^{44}$ reported abnormal EMG findings in the distribution of the inferior gluteal nerve and the tibial and peroneal divisions of the sciatic nerve in six of eight patients who were later shown to have adhesions between the piriformis muscle, sciatic nerve and the roof of the greater sciatic notch. They suggested that these findings confirmed extra pelvic compression of the sciatic nerve. No specific needle EMG or further information regarding their EMG findings was provided.

In 1990, Chang and $\mathrm{Lien}^{45}$ reported on the comparison of EMG versus spinal nerve stimulation in patients with L5 or S1 radiculopathies. They found that in 17 patients with objective clinical evidence of radiculopathy including a neurological deficit, the EMG was abnormal in 10 (59\%), whereas amplitude and area differences in spinal nerve stimulation were noted in 16 (94\%) and 12 patients (71\%), respectively. More recently, Chang et $\mathrm{al}^{46}$ measured motor nerve conduction velocity using magnetic stimulation in the sciatic nerve in patients who met all three criteria for diagnosis proposed by Fishman et al ${ }^{47}$ (sciatica or gluteal pain in the FAIR position, focal tenderness in the sciatic notch and a positive Lasègue sign). They detected significant slowing of motor nerve conduction velocity in the gluteal component of the L5 root (L5 root to gluteal fold) versus healthy controls, whereas there was no difference in CMAP amplitude recording from the tibialas anterior (TA) or gastrocnemius.

Looking specifically at the use of electrodiagnostic testing in patients with piriformis syndrome while using an epidural electrode positioned at S3-4, Nakamura et $\mathrm{al}^{48}$ recorded action potentials from the cauda equina in two patients with piriformis syndrome symptoms. Recording was completed with the hip and knee fully extended, the hip flexed and then the hip both flexed and internally rotated in order to stretch the piriformis muscle and increase its compressive effect upon the sciatic nerve. They detected a $30 \%$ decrease in amplitude in the piriformis-stretch position on the symptomatic side, versus just a $10 \%$ decrease in the other two hip positions on the contralateral side. Similarly, Fishman et $\mathrm{al}^{47}$ documented significant prolongation of both the posterior tibial and peroneal H-reflexes in symptomatic patients whose hips are in the FAIR position (flexed, adducted and internally rotated), and noted that when clinical criteria and response to treatment were used to define it, a more than three standard deviation increase (specific for the condition) was found $83 \%$ of the time. Interestingly, the results of these last two studies ${ }^{47,48}$ coincide with the results of a study on ten cadavers, ${ }^{26}$ in which the FAIR or piriformis "stretch" position resulted in narrowing of the infra-piriformis foramen, the sciatic nerve being closer to the ischial spine of the hip, and an increase in the angle between the sciatic nerve and the transverse plane. The Fishman studies are the only ones in the current literature to demonstrate abnormalities and prolongation in the FAIR position of the H-reflex..$^{32,47}$ This conclusion must be treated with caution, as a critical review of the data in this non-standard diagnostic test suggests that the data does not make intuitive sense. As such, replication in another setting is required but most importantly must be done in a standardized fashion in patients with an established set of agreed upon diagnostic criteria in order for implementation into electrophysiological laboratories. The H-reflex itself requires further discussion. Most electrophysiological laboratories perform H-reflex from the soleus or gastrocnemius and there are normative and side-to-side comparison data available. There is no such data available for the peroneal H-reflex recording from the tibialis anterior, peroneus longus or extensor digitorum longus (EDL). The original study by Fishman et $\mathrm{al}^{47}$ which describes this technique has a number of significant flaws related to the onset latency of the monosynaptic response. We have suggested that the H-reflex is more sensitive as a diagnostic tool to amplitude than to a delay in onset latency. ${ }^{49}$ The recording of H-reflexes with facilitation is required for the tibialis anterior, peroneus longus or EDL and is fraught with many technical difficulties. The motor control literature would suggest that when using the H-reflex to document motoneuron excitability, or when assessing facilitation and inhibition, there are complex influences on the activity dependent changes in the motor pathway. ${ }^{50,51}$ The effects of hip joint angle on H-reflex excitability in humans suggests that there are many important factors that may impact the amplitude, with depressed H-reflex excitability with the hip flexed.52 At best, this makes commenting on amplitude a challenge and at worst, makes the H-reflex highly suspect as an accurate diagnostic tool. Conceptually however, the idea of obtaining a long latency response from a peroneal innervated muscle makes sense but requires validation, in a clinical setting, using the proposed criteria.

Electrodiagnostic testing requires proximal stimulation above the piriformis muscle, with an attempt to demonstrate focal slowing and or conduction block across the piriformis muscle. This requires near nerve stimulation or root stimulation in the prone plus FAIR positions in order to reproduce symptoms. This technique has not been published nor is it available in most standard electrodiagnostic laboratories. In our opinion, the results of the Chang et al study, ${ }^{46}$ requires further study.

Proposed EDX Criteria in evaluating patients with Sciatic Nerve Injury/ Palsy(*):

1. Standard Motor and Sensory studies in the lower limb bilaterally with a $>50 \%$ reduction of CMAP and/or SNAP amplitude with side-to-side comparison

2. Greater than $1 \mathrm{msec}$ difference between sides of Soleus Hreflex latency

3. Evidence of axonal loss in muscles innervated by the sciatic nerve on needle EMG of muscles below the piriformis muscle, and paraspinal muscle EMG must be normal to exclude a radiculopathy 
*The term palsy is an old fashioned word and strictly speaking means muscle weakness. As such, a nerve cannot suffer a palsy. This term is often used/misused when discussing nerve damage.

As stated above further research is needed to determine the side-to-side differences of $\mathrm{H}$-reflexes from the soleus and peroneus muscles in various postions e.g. FAIR. Furthermore, electrophysiological studies are providing important and objective neurophysiological information about clinical conditions that may mimic PS, not diagnose it.

\section{Treatment of Piriformis Syndrome}

Initial non-operative treatment typically consists of medications (non-steroidal anti-inflammatory drugs (NSAID), muscle relaxants, other medications effective in neuropathic pain such as pregabalin or gabapentin) and physiotherapy. Physiotherapy concentrates on piriformis stretching, and isometric strengthening. Therapists often use the FAIR position described above in education and treatment. However, there have been no reported studies in physiotherapy that compare one technique to the other. The technique of post-isometric relaxation is a common and helpful addition as are the stretching techniques of reciprocal inhibition. . $^{53,54}$

Local injection therapy is a mainstay and may be both diagnostic and therapeutic. Injections may include local anaesthetic, steroid, both a local anaesthic and steroid or, more recently, botulinum toxin (BTX). Fishman et $\mathrm{al}^{32}$ studied 353 patients with a diagnosis of PS (using standardized criteria) with a combination of physiotherapy and a local injection of lidocaine and triamcinolone. Results showed that $79 \%$ of patients experienced at least a $50 \%$ reduction in pain at an average of 16 months post-treatment. Different studies report a variety of methods to guide injections including imaging, ${ }^{18,20,40,55,56}$ fluoroscopy ${ }^{16,57,58}$ and EMG. ${ }^{21,32,59,60}$

In terms of prolonged pain relief, some of the most encouraging results are found with the use of botulinum toxin. Lang $^{21}$ reported on 20 patients treated with 5000 units of BTX$\mathrm{B}$ and noted that $95 \%$ of patients reported fair to excellent improvement in pain. Fishman ${ }^{60}$ attempted to establish doseresponse curves for BTX-B in PS and concluded that 12,500 units was safe and most efficacious. Porta ${ }^{10}$ and Childers ${ }^{31}$ both reported positive outcomes using BTX-A in PS. Childers ${ }^{31}$ inclusion and exclusion criteria would meet the proposed criteria outlined below.

There are no prospective, randomized trials that use surgery to treat PS. Rather, a number of small case studies report positive results using non-validated outcome measures. ${ }^{41,44,61}$ Benson $^{44}$ reported on 14 patients with post-traumatic PS that were treated with piriformis tenotomy and sciatic neurolysis. Eight of the 14 patients underwent pre-operative EMG testing and of the eight patients, six showed extra-pelvic compression of the sciatic nerve. On a non-validated outcome scale, the study reported that there were 11 excellent and 4 good results. Filler and colleagues ${ }^{40}$ have described the use of surgical resection for PM in 62 patients with piriformis syndrome who had not obtained relief by local anaesthetic injections. They found $59 \%$ had an excellent outcome and 4\% showed no benefit. Both Tiel ${ }^{5}$ and Stewart ${ }^{4}$ have criticized the conclusions of this paper.
Most surgeons treating patient(s) with symptoms suggestive of PS require a reasonable yet unsuccessful period of conservative treatment (i.e. physiotherapy, imaging and electrodiagnostic findings) in order to rule out other causes of sciatic nerve involvement. A brief yet consistent response to injection with local anaesthetic and/or BTX may also be involved. Utilization of these treatments may increase the frequency of symptom improvement, however there are no guarantees.

\section{Conclusions}

The diagnosis of PS remains controversial due to a lack of definitive diagnostic criteria. Stewart's ${ }^{4,14}$ suggestion to base the diagnosis on a template previously utilized for thoracic outlet syndrome (TOS) is reasonable but must be reviewed as the use of such criteria to diagnose TOS has not completely stopped the controversy of that diagnosis in the upper extremity. Papers such as that of Hopayian ${ }^{29}$ are useful attempts to bring some clarity to the diagnostic criteria.

In conclusion, from the perspective of the electromyographer, there is a role for EMG, nerve conduction studies, and nerve stimulation in the diagnosis and management of PS. The specifics and magnitude of their roles however, must be tested further within the confines of formal comparative clinical trials. It appears at present that the most important aspect of electrodiagnostic testing is for ruling out more common conditions and evaluating the differential diagnosis (e.g., peroneal nerve entrapment, an L5 radiculopathy, or a sciatic nerve palsy).

We do not feel that criteria are required for the entity described by Stewart, ${ }^{4,14}$ as neurogenic or post-traumatic PS. These are proximal sciatic neuropathies which can be differentiated from the controversial entity known as PS. We suggest that the following criteria be used to describe the nonspecific piriformis syndrome:

Proposed Criteria for the classification of Piriformis Syndrome

1. Buttock and leg pain made worse with sitting, stair climbing and/or leg crossing

2. Pain and tenderness to palpation of the sciatic notch area (piriformis muscle) and pain with increased PM tension

3. No evidence of axonal loss to the sciatic nerve on electrophysiological testing

4. No evidence of abnormal imaging or other entity that could explain the presenting features of sciatica (e.g. radiculopathy, tumor, etc.)

5. Reduction of $>60 \%$ of buttock and leg pain with diagnostic injection into the piriformis muscle under radiographic imaging (Fluoroscopic or Ultrasound) and or EMG guidance

Given that a true gold standard for diagnosis is difficult to establish, it is suggested that a positive outcome from standard PS treatments on a prospective trial would validate the criteria. This analysis would be similar to how other syndromes are evaluated and studied and will include the development of diagnostic criteria. We are proposing that as in the classification and diagnosis of rheumatic diseases, a set of criteria can be used as guidelines for classification of disease syndromes, for the purpose of patients taking part in clinical investigation. One 
must be cautious in such application because criteria can be developed with several different purposes in mind, e.g. to classify a group of patients, diagnose individual patients, or to estimate disease frequency and or to determine prognosis. In this case we are suggesting the above as diagnostic criteria, as a way to select patients for future therapeutic trials.

\section{ACKNOWLEDGEMENTS}

The authors thank Heather Askes for assistance with the manuscript.

\section{REFERENCES}

1. Jroundi L, El QA, Chakir N, El Hassani MR, Jiddane M. [The piriformis syndrome: a rare cause of non discogenic sciatica. A case report]. J Radiol. 2003;84(6):715-7.

2. McCrory $\mathrm{P}$. The "piriformis syndrome"--myth or reality? $\mathrm{Br} \mathrm{J}$ Sports Med. 2001;35(4):209-10.

3. Read MT. The "piriformis syndrome"--myth or reality? Br J Sports Med. 2002;36(1):76.

4. Stewart JD. The piriformis syndrome is overdiagnosed. Muscle Nerve. 2003;28(5):644-6.

5. Tiel RL. Piriformis and related entrapment syndromes: myth \& fallacy. Neurosurg Clin N Am. 2008;19(4):623-7, vii.

6. Parziale JR, Hudgins TH, Fishman LM. The piriformis syndrome. Am J Orthop. 1996;25(12):819-23.

7. Silver JK, Leadbetter WB. Piriformis syndrome: assessment of current practice and literature review. Orthopedics. 1998;21(10): $1133-5$.

8. Campbell WW, Landau ME. Controversial entrapment neuropathies. Neurosurg Clin N Am. 2008;19(4):597-vii.

9. Kirschner JS, Foye PM, Cole JL. Piriformis syndrome, diagnosis and treatment. Muscle Nerve. 2009;40(1):10-8.

10. Porta M. A comparative trial of botulinum toxin type A and methylprednisolone for the treatment of myofascial pain syndrome and pain from chronic muscle spasm. Pain. 2000;85 $((1-2)): 101-5$.

11. Boyajian-O'Neill LA, McClain RL, Coleman MK, Thomas PP. Diagnosis and management of piriformis syndrome: an osteopathic approach. J Am Osteopath Assoc. 2008;108(11): 657-64.

12. Windisch G, Braun EM, Anderhuber F. Piriformis muscle: clinical anatomy and consideration of the piriformis syndrome. Surg Radiol Anat. 2007;29(1):37-45.

13. Pecina HI, Boric I, Smoljanovic T, Duvancic D, Pecina M. Surgical evaluation of magnetic resonance imaging findings in pririformis muscle syndrome. Skeletal Radiol. 2008;37:1019-23.

14. Stewart JD. Focal Peripheral Neuropathies. In: Anon. West Vancouver: JBJ Publishing; 2010. p. 443-8.

15. Wilbourn AJ. Thoracic outlet syndrome is overdiagnosed. Muscle Nerve. 1999;22(1):130-6.

16. Benzon HT, Katz JA, Benzon HA, Iqbal MS. Piriformis syndrome: anatomic considerations, a new injection technique, and a review of the literature. Anesthesiology. 2003;98(6):1442-8.

17. Bernard TN Jr, Kirkaldy-Willis WH. Recognizing specific characteristics of nonspecific low back pain. Clin Orthop Relat Res. 1987;217:266-80.

18. Fanucci E, Masala S, Sodani G et al. CT-guided injection of botulinic toxin for percutaneous therapy of piriformis muscle syndrome with preliminary MRI results about denervative process. Eur Radiol. 2001;11(12):2543-8.

19. Hallin RP. Sciatic pain and the piriformis muscle. Postgrad Med. 1983;74(2):69-72.

20. Huerto AP, Yeo SN, Ho KY. Piriformis muscle injection using ultrasonography and motor stimulation--report of a technique. Pain Physician. 2007;10(5):687-90.

21. Lang AM. Botulinum toxin type B in piriformis syndrome. Am $\mathbf{J}$ Phys Med Rehabil. 2004;83(3):198-202.

22. Papadopoulos EC, Khan SN. Piriformis syndrome and low back pain: a new classification and review of the literature. Orthop Clin North Am. 2004;35(1):65-71.
23. Rodrigue T, Hardy RW. Diagnosis and treatment of piriformis syndrome. Neurosurg Clin N Am. 2001;12(2):311-9.

24. Anon. Gray's Anatomy. The anatomical basis of clinical practice. Amsterdam: Elsevier; 2005.

25. Russell JM, Kransdorf MJ, Bancroft LW et al. Magnetic resonance imaging of the sacral plexus and piriformis muscles. Skeletal Radiol. 2008;37(8):709-13.

26. Guvencer M, Akyer P, Iyem C, Tetik S, Naderi S. Anatomic considerations and the relationship between the piriformis muscle and the sciatic nerve. Surg Radiol Anat. 2008;30(6): 467-74.

27. Pecina M. Contribution to the etiological explanation of the piriformis syndrome. Acta Anat (Basel). 1979;105(2):181-7.

28. Barton PM. Piriformis syndrome: a rational approach to management. Pain. 1991;47(3):345-52.

29. Hopayian K, Song F, Riera R, Sambandan S. The clinical features of the piriformis syndrome: a systematic review. Eur Spine J. 2010; 19(12):2095-109.

30. Beatty RA. The piriformis muscle syndrome: a simple diagnostic maneuver. Neurosurgery. 1994;34(3):512-4.

31. Childers MK, Wilson DJ, Gnatz SM, Conway RR, Sherman AK. Botulinum Toxin Type A Use in Piriformis Muscle Syndrome A Pilot. Am J Phys Med Rehabil. 2002;81(10):751-9.

32. Fishman LM, Dombi GW, Michaelsen C et al. Piriformis syndrome: diagnosis, treatment, and outcome--a 10-year study. Arch Phys Med Rehabil. 2002;83(3):295-301.

33. Jankiewicz JJ, Hennrikus WL, Houkom JA. The appearance of the piriformis muscle syndrome in computed tomography and magnetic resonance imaging. A case report and review of the literature. Clin Orthop Relat Res. 1991;(262):205-9.

34. Karl RD Jr, Yedinak MA, Hartshorne ME et al. Scintigraphic appearance of the piriformis muscle syndrome. Clin Nucl Med. 1985;10(5):361-3

35. Lee EY, Margherita AJ, Gierada DS, Narra VR. MRI of piriformis syndrome. AJR Am J Roentgenol. 2004;183(1):63-4.

36. Rossi P, Cardinali P, Serrao M et al. Magnetic resonance imaging findings in piriformis syndrome: a case report. Arch Phys Med Rehabil. 2001;82(4):519-21.

37. Sayson SC, Ducey JP, Maybrey JB, Wesley RL, Vermilion D. Sciatic entrapment neuropathy associated with an anomalous piriformis muscle. Pain. 1994;59(1):149-52.

38. Filler AG, Kliot M, Howe FA et al. Application of magnetic resonance neurography in the evaluation of patients with peripheral nerve pathology. J Neurosurg. 1996;85(2):299-309.

39. Filler AG, Maravilla KR, Tsuruda JS. MR neurography and muscle MR imaging for image diagnosis of disorders affecting the peripheral nerves and musculature. Neurol Clin. 2004;22(3): 643-82.

40. Filler AG, Haynes J, Jordan SE et al. Sciatica of nondisc origin and piriformis syndrome: diagnosis by magnetic resonance neurography and interventional magnetic resonance imaging with outcome study of resulting treatment. J Neurosurg Spine. 2005;2(2):99-115.

41. Filler AG. Piriformis and related entrapment syndromes: diagnosis \& management. Neurosurg Clin N Am. 2008;19(4):609-22, vii.

42. Kipervas IP, Ivanov LA, Urikh EA, Pakhomov SK. [Clinicoelectromyographic characteristics of piriform muscle syndromes]. Zh Nevropatol Psikhiatr Im S S Korsakova. 1976; 76(9):1289-92.

43. Synek V. Short latency somatosensory evoked potentials in patients with painful dysaesthesias in peripheral nerve lesions. Pain. 1987;29(1):49-58.

44. Benson ER, Schutzer SF. Posttraumatic piriformis syndrome: diagnosis and results of operative treatment. J Bone Joint Surg Am. 1999;81(7):941-9.

45. Chang C-W, Lien I-N. Spinal nerve stimulation in the diagnosis of lumbosacral radiculopathy. Am J Phys Med Rehabil. 1990;69 (6):318-22.

46. Chang CW, Shieh SF, Li CM, Wu WT, Chang KF. Measurement of motor nerve conduction velocity of the sciatic nerve in patients with piriformis syndrome: a magnetic stimulation study. Arch Phys Med Rehabil. 2006;87(10):1371-5 
47. Fishman LM, Zybert PA. Electrophysiologic evidence of piriformis syndrome. Arch Phys Med Rehabil. 1992;73(4):359-64.

48. Nakamura H, Seki M, Konishi S, Yamano Y, Takaoka K. Piriformis syndrome diagnosed by cauda equina action potentials: report of two cases. Spine. 2003;28(2):E37-E40.

49. Miller TA, Pardo R, Yaworski R. Clinical utility of reflex studies in assessing radiculopathy. Muscle Nerve. 1999;22(8):1075-9.

50. Giesebrecht S, Martin PG, Gandevia SC, Taylor JL. Facilitation and inhibition of tibialis anterior responses to corticospinal stimulation after maximal voluntary contractions. J Neurophysiol. 2010;103(3):1350-6.

51. Kuwabara S, Cappelen-Smith C, Lin CS, Mogyoros I, Burke D. Effects of voluntary activity on the excitability of motor axons in the peroneal nerve. Muscle Nerve. 2002;25(2):176-84.

52. Knikou M, Rymer Z. Effects of changes in hip joint angle on $\mathrm{H}-$ reflex excitability in humans. Exp Brain Res. 2002;143(2): 149-59.

53. Lewit K, Simons DG. Myofascial pain: relief by post-isometric relaxation. Arch Phys Med Rehabil. 1984;65(8):452-6.

54. Retzlaff EW, Berry AH, Haight AS et al. The piriformis muscle syndrome. J Am Osteopath Assoc. 1974;73(10):799-807.
55. Reus M, de Dios BJ, Vazquez V, Redondo MV, Alonso J. Piriformis syndrome: a simple technique for US-guided infiltration of the perisciatic nerve. Preliminary results. Eur Radiol. 2008;18(3): 616-20.

56. Smith J, Hurdle MF, Locketz AJ, Wisniewski SJ. Ultrasoundguided piriformis injection: technique description and verification. Arch Phys Med Rehabil. 2006;87(12):1664-7.

57. Bennett JD, Miller TA, Richards RS. The use of Botox in interventional radiology. Tech Vasc Interv Radiol. 2006;9(1): 36-9.

58. Betts A. Combined fluoroscopic and nerve stimulator technique for injection of the piriformis muscle. Pain Physician. 2004;7:279-81.

59. Fishman LM, Anderson C, Rosner B. Botox and physical therapy in the treatment of piriformis syndrome. Am J Phys Med Rehabil. 2002;81(12):936-42.

60. Fishman LM, Konnoth C, Rozner B. Botulinum neurotoxin type B and physical therapy in the treatment of piriformis syndrome: a dose-finding study. Am J Phys Med Rehabil. 2004;83(1):42-50.

61. Dezawa A, Kusano S, Miki H. Arthroscopic release of the piriformis muscle under local anesthesia for piriformis syndrome. Arthroscopy. 2003;19(5):554-7. 